\title{
КАРТОГРАФИЧЕСКИЙ МЕТОД ИССЛЕДОВАНИЯ ФАКТОРОВ, ВЛИЯЮЩИХ НА РАЗВИТИЕ ЦИФРОВОЙ ЭКОНОМИКИ РЕГИОНА
}

\section{Алена Евгеньевна Донская}

Сибирский государственный университет геосистем и технологий, 630108, Россия, г. Новосибирск, ул. Плахотного, 10, обучающийся, тел. (952)904-78-39, e-mail: chydo_98@mail.ru

\section{Екатерина Владимировна Китаева}

Сибирский государственный университет геосистем и технологий, 630108, Россия, г. Новосибирск, ул. Плахотного, 10, обучающийся, тел. (999)452-57-98, e-mail: katerina_kitaeva20@mail.ru

\section{Людмила Константиновна Радченко}

Сибирский государственный университет геосистем и технологий, 630108, Россия, г. Новосибирск, ул. Плахотного, 10, кандидат технических наук, доцент кафедры картографии и геоинформатики, тел. (913)909-51-88, e-mail: rlk77@mail.ru

Новосибирская область - это мощный научно-образовательный, инновационный, институциональный, инфраструктурный и культурный регион. Учитывая стратегию социальноэкономического развития Новосибирской области, и использования картографического метода исследования, в статье затронут вопрос о факторах, влияющих на развитие цифровой экономики региона, которые будут использованы при создании познавательной модели Новосибирской области. Факторы охватывают все природные и неприродные ресурсы, которые представлены в регионе. Отдельное внимание уделено гидроресурсам, а конкретно изучено экономическое значение реки Обь для региона. Выявлены неиспользуемые ресурсы, которые с точки зрения инвестирования интересны для планирования и развития региона. развитие

Ключевые слова: цифровая экономика, промышленность, население, экономическое

\section{CARTOGRAPHIC METHOD OF STUDYING THE FACTORS INFLUENCING THE DEVELOPMENT OF THE DIGITAL ECONOMY OF THE REGION}

\section{Alena Y. Donskaya}

Siberian State University of Geosystems and Technologies, 10, Plakhotnogo St., Novosibirsk, 630108, Russia, Student, phone: (952)904-78-39, e-mail: chydo_98@mail.ru

\section{Ekaterina V. Kitaeva}

Siberian State University of Geosystems and Technologies, 10, Plakhotnogo St., Novosibirsk, 630108, Russia, Student, phone: (999)452-57-98, e-mail: katerina_kitaeva20@mail.ru

\section{Lyudmila K. Radchenko}

Siberian State University of Geosystems and Technologies, 10, Plakhotnogo St., Novosibirsk, 630108, Russia, Ph. D., Associate Professor, Department of Cartography and Geoinformatics, phone: (913)909-51-88, e-mail: 1.k.radchenko@sgugit.ru

The Novosibirsk Region is a powerful scientific and educational, innovation, institutional, infrastructural and cultural region. Taking into account the Strategy for the socio-economic development of the Novosibirsk Region, and the use of the cartographic method of research, the article ad- 
dresses the issue of factors affecting the development of the digital economy of the region, which will be used to create a cognitive model of the Novosibirsk Region. The factors cover all natural and non-natural resources that are represented in the region. Special attention is paid to water resources, and economic significance of the $\mathrm{Ob}$ River for the region is studied specifically. Unused resources that are interesting for planning and development of the region from the point of view of investment are identified.

Keywords: digital economy, industry, population, economic development

\section{Введение}

Современное развитие экономики происходит под влиянием новых глобальных финансово-экономических и технологических изменений [1]. Большинство развитых стран мира для увеличения своей конкурентоспособности, повышения эффективности экономики, улучшения качества жизни населения стремятся использовать различные инновационные технологии, в том числе информационные, телекоммуникационные, передовые производственные и ряд других, что подразумевает переход к новому этапу развития постиндустриальной экономики, называемой «цифровой экономикой» [18, 19]. Цифровизация уже сегодня затрагивает все основные сферы экономики и жизнедеятельности, и ее влияние в будущем будет только увеличиваться [2, 3].

Цель данного исследования - выявить все факторы, которые влияют на развитие региона с целью инвестирования в сфере экономики и жизнедеятельности человека. В рамках исследования предстоит изучить социальноэкономическое значение Новосибирской области во всех сферах жизнедеятельности с помощью картографического метода исследования.

\section{Memodbl}

В исследовании использовался теоретический и картографический методы исследования. Используя литературные источники, изучена роль промышленности на развитие цифровой экономики Новосибирской области, изучено влияние на цифровую экономику объектов рекреации и промышленности, расположенных вдоль реки Обь. Также изучены неиспользуемые ресурсы, которые интересны с точки зрения инвестирования.

Картографический метод исследования направлен на получение и анализ информации с целью более глубокого познания объектов и явлений. С помощью физической карты изучается выгодное географическое положение Новосибирской области по отношению к другим областям и странам. Опираясь на различные общегеографические и тематические карты, определяются факторы, влияющие на развитие экономики региона. Кроме того, картографический метод исследования проявляется не только при использовании карт, но и при их создании. Данное исследование направлено на анализ и выявление факторов развития цифровой экономики региона путем создания познавательной модели региона. 


\section{Выявление факторов, влияющих на развитие цифровой экономики региона}

Новосибирская область - одна из наиболее индустриально развитых областей на территории Сибирского федерального округа. Срединное положение в Южной Сибири в окружении Омской, Томской, Кемеровской областей и Алтайского края при современном уровне транспортных средств и магистралей делает ее ядром высокой экономической активности. Новосибирская область обладает большими ресурсами, которые в настоящий период времени недостаточно используются (рис. 1) $[9,17]$.

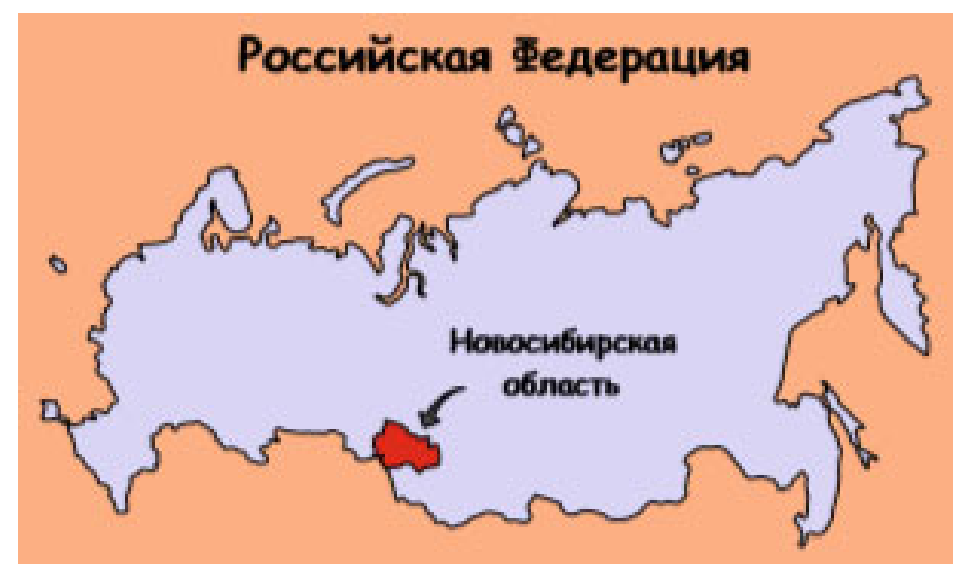

Рис. 1. Географическое положение Новосибирской области [8].

Все ресурсы региона подразделяются на природные и неприродные. К неприродным относят ресурсы, созданные человеком - это трудовые, интеллектуальные, историко-культурные [4]. Согласно оперативным данным Росстата от 23.04.2020 «Численность постоянного населения РФ по муниципальным образованиям на 1 января 2020 г.», численность населения Новосибирской области на 1 января 2015 года составляла 2746822 чел., на 1 января 2020 года 2798170 чел., что говорит о приросте населения.

Самый большой город в Новосибирской области по населению - Новосибирск, далее Бердск и Искитим. В регионе всего 2 города с численностью от 100 тысяч человек.

В регионе разработана и совершенствуется законодательная и нормативноправовая база, стимулирующая и поддерживающая развитие инновационной деятельности. В целях формирования привлекательных условий для жизни и профессиональной деятельности высококвалифицированных научных, управленческих и производственных кадров разработаны и утверждены соответствующие программы, например стратегия социально-экономического развития региона на период до 2030 года, утвержденная правительством Новосибирской области [14].

Создается и развивается инфраструктура инновационной деятельности региона: технопарки («Технопарк Новосибирского Академгородка», технопарк «Ново- 
сибирск», технопарк в сфере биотехнологий в наукограде Кольцово), медтехнопарк, бизнес-инкубаторы, в том числе при образовательных учреждениях.

В рамках Государственной программы «Создание в Российской Федерации технопарков в сфере высоких технологий» реализуется крупный инфраструктурный проект - создание Технопарка Новосибирского Академгородка (Академпарк) [11].

Новосибирская область отличается мощным научно-образовательным потенциалом. Ученые города составляют $5 \%$ всего российского научного сообщества и почти половину числа ученых в Сибири. Цитируемость научных публикаций новосибирских исследователей в среднем в 2-3 раза выше средних показателей соседних регионов [14].

Область привлекательна для туристов своими историко-культурными и туристско-познавательными объектами (рис. 2), что способствует привлечению в регион туристов, тем самым обеспечивая устойчивое развитие туристской отрасли в отдельности, так и общей экономики региона.

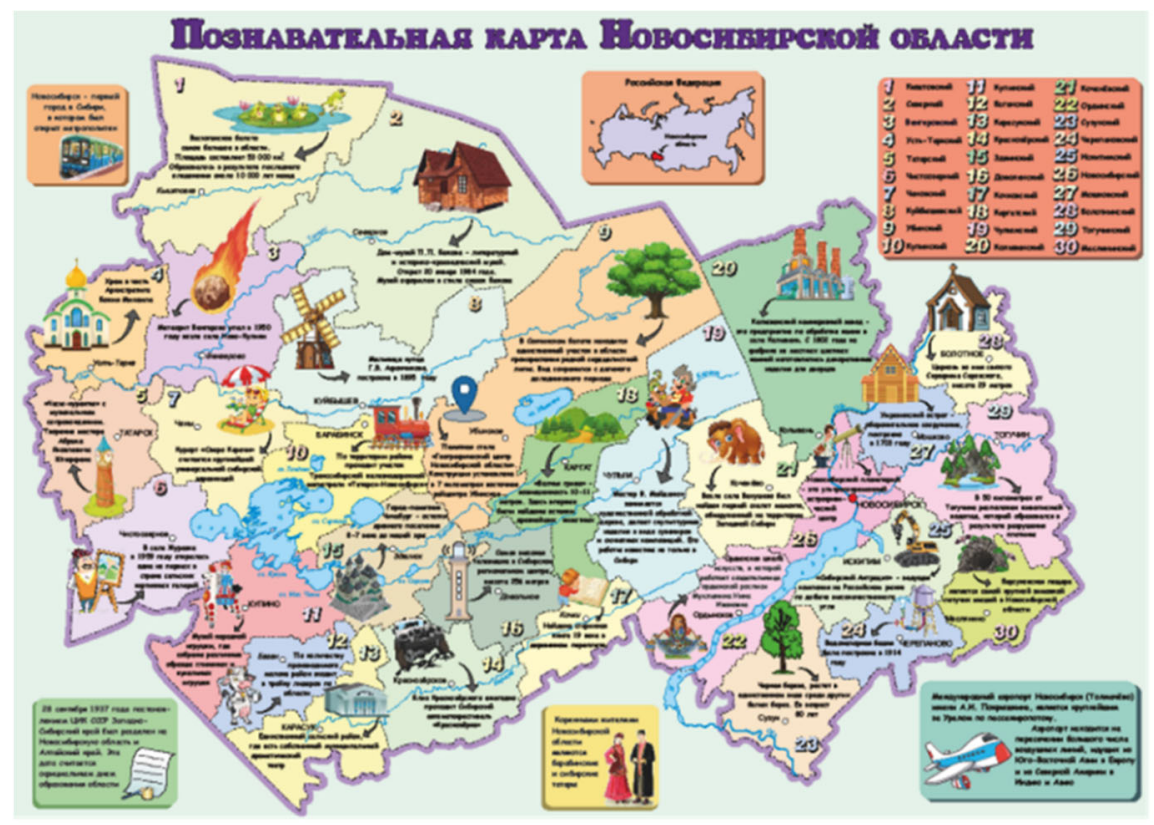

Рис. 2. Познавательная карта Новосибирской области

Промышленный комплекс занимает ведущее положение и составляет почти $1 / 5$ часть экономики Новосибирской области. Создает около $10 \%$ всей промышленной продукции в России, основная часть которой приходится на предприятия тяжелой промышленности, расположенные главным образом в Новосибирске, Искитиме и Бердске. В структуре промышленного производства доминируют обрабатывающие отрасли промышленности, машиностроение, металлообработка, электроэнергетическая и пищевая отрасли, а также цветная металлургия [5].

В товарной структуре экспорта и импорта традиционно первое место занимает машиностроение и производство оборудования. На втором месте - экспорт продукции химической промышленности, на третьем месте - минераль- 
ные продукты. Крупнейшие страны-партнеры - Китай, Украина, Казахстан, США, Индия, Франция, Германия, Беларусь, Болгария, Венесуэла.

Новосибирская область обеспечивает 20 \% машиностроительной продукции Сибири. Прирост промышленного производства отмечен в обработке древесины и производстве изделий из дерева, химическом производстве, производстве резиновых и пластмассовых изделий, издательской и полиграфической деятельности, в производстве пищевых продуктов. При этом снижено производство прочих неметаллических минеральных продуктов, электрооборудования, изделий из кожи и производство обуви, текстильное и швейное производство [15].

Доля сельского хозяйства в валовом продукте области всего 9 \%. Сельскохозяйственная освоенность территории области не слишком высока ( $\approx 4 \%$ ), но на Новосибирскую область приходится четверть всех сельскохозяйственных угодий Западной Сибири.

Природные ресурсы: основные полезные ископаемые, добываемые в области: каменный уголь, торф, тугоплавкие глины, месторождения природного газа и нефти [7]. Запасы торфа оцениваются в 7,2 млрд. тонн, однако в связи с высокими затратами на его добычу и переработку, разработка торфяных месторождений практически не ведется.

Также на экономическое развитие Новосибирской области влияют гидроресурсы. Обь - главная река бассейна протяженностью в пределах Новосибирской области около 400 км [10]. На Оби находится единственная ГЭС - в г. Новосибирск, которая играет важную роль в энергосистеме Новосибирска, обеспечении надежного водоснабжения, работе речного транспорта $[6,13]$.

На р. Обь расположена насосная станция НФС-1, которая на сегодняшний день подает в город свыше 250 тыс. куб. м. воды в сутки (рис. 3). Если заглянуть в ближайшую перспективу, то станция будет способна дать Новосибирску еще 100 тыс. куб. м. воды в сутки [6]. В центре Новосибирска расположен порт - основными видами деятельности являются погрузочно-разгрузочные работы и связанные с ними услуги, добыча и реализация нерудных строительных материалов (песка). Почти весь добытый песок поставляется предприятиям и организациям города.

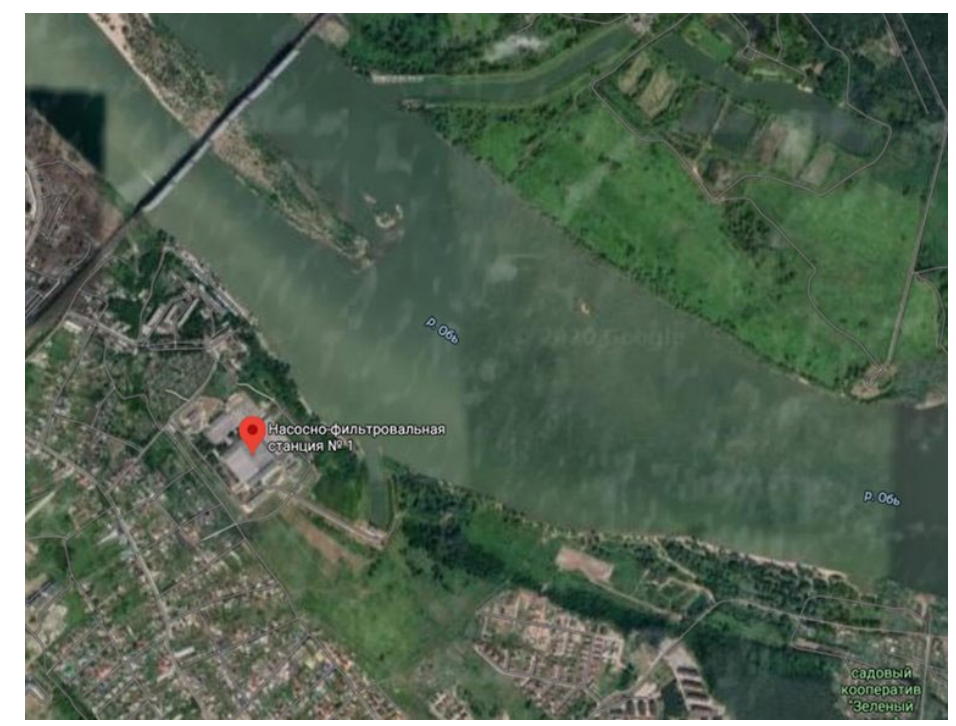

Рис. 3. Месторасположение НФС-1 на космическом снимке 
Порт также осуществляет перевозки пассажиров речными судами на пригородных линиях, прогулочные, экскурсионные и туристические рейсы по живописным местам Оби и водохранилища, обеспечивает работу паромной переправы «Ордынск - Нижняя Каменка». Кроме того, вдоль реки есть множество санаториев и домов отдыха, таких как СНТ «ОТДЫХ-2», МБУ центр «Обские зори», санаторий Парус, санаторий Ельцовка и множество других.

Более 50 различных видов рыб обитает в Оби. Ловля рыбы влияет на развитие пищевой промышленности, что непосредственно оказывает влияние на цифровую экономику региона (рис. 4) [12].

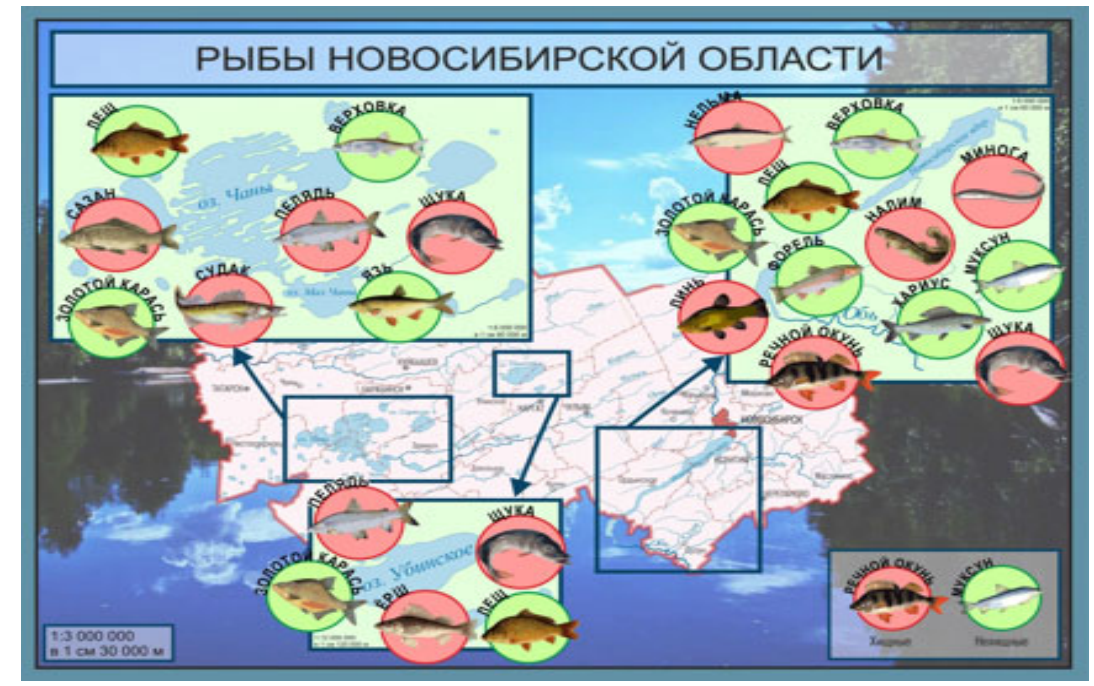

Рис. 4. Карта «Рыбы Новосибирской области»

Кроме того, вдоль течения р. Обь в пределах Новосибирской области есть множество островов, которые никак не используются, хотя с точки зрения инвестирования они очень интересны для планирования и строительства различных туристско-рекреационных объектов (рис. 5) [16].
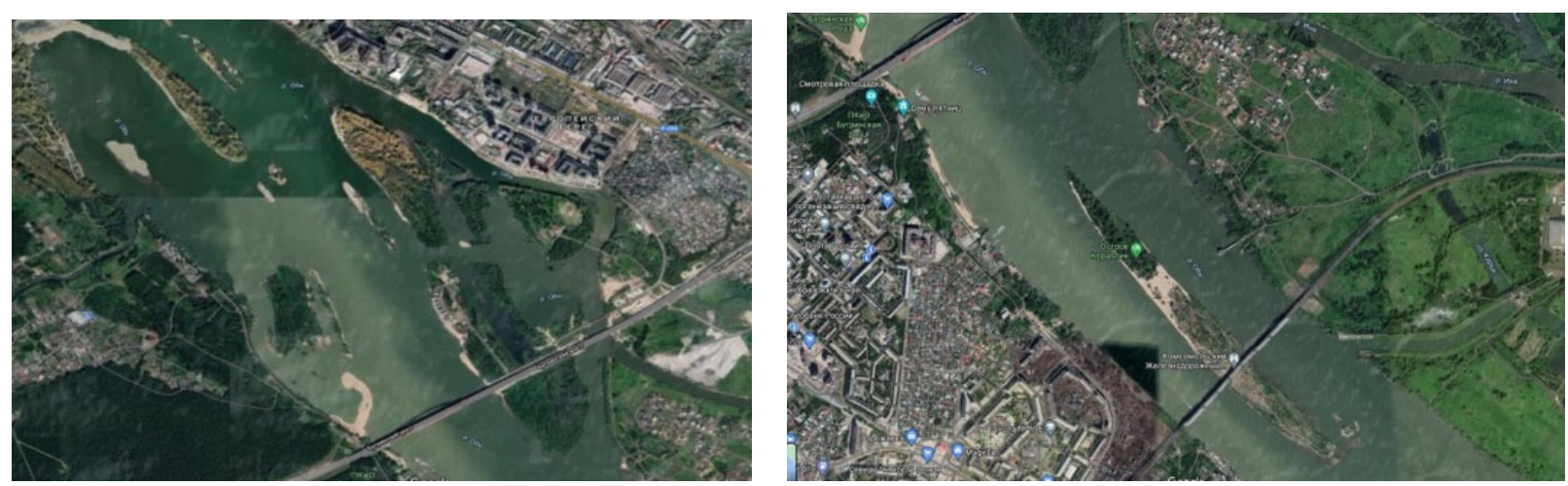

Рис. 5. Фрагменты космических снимков островов на реке Обь 


\section{Заключение}

В ходе исследования были выявлены факторы, способствующие развитию цифровой экономики региона. В стратегии по социально-экономическому развитию региона особое внимание уделяется сельскому и лесному хозяйству, добыче полезных ископаемых, уделяется внимание потребителям и заказчикам местной продукции различных производств, высококвалифицированным рабочим кадрам, крупным научно-исследовательским центрам, промышленным (машиностроительным, химическим и иным) инновационным предприятиям.

Кроме того, факторами, влияющими на развитие цифровой экономики региона можно считать:

- географическое положение;

- природные условия;

- климатические условия;

- население;

- развитие промышленности и сельского хозяйства;

- туризм и рекреационные ресурсы;

- частное и государственное финансирование.

Все эти факторы будут использованы при создании познавательной модели с послойной тематической информацией Новосибирской области с целью развития цифровой экономики региона.

\section{БИБЛИОГРАФИЧЕСКИЙ СПИСОК}

1. Абдрахманова, К.О. Цифровая экономика 2020 [Текст]: краткий статистический сборник / К.О. Абдрахманова, Л.М. Вишневский - М.: НИУ ВШЭ, 2020. - 112 с.

2. Анохина, Л.В. Роль цифровизации экономики в модернизации промышленных предприятий [Текст]: статья в журнале / Л.В. Анохина - Калуга: Калужский филиал РАНХиГС, 2018. -11 c.

3. Батракова, Л.Г. Развитие цифровой экономики в регионах России [Текст]: учебник / Л.Г. Батракова - М.: Логос, 2019. - 64 с.

4. Виды ресурсов региона и задачи их рационального использования [Электронный ресурс] - Режим доступа: https:// https://studbooks.net/ - Загл. с экрана.

5. Жендарева, Е.С. Оценка эффективности добычи и доставки нерудных строительных материалов в новосибирском речном порту [Текст]: статья в журнале / Е.С. Жендарев - Новосибирск: ФГБОУ ВО «Сибирский государственный университет водного транспорта», 2015. $-49 \mathrm{c}$.

6. Жмодик, Р. Первая на Оби. 55 лет Новосибирской ГЭС [Текст]: учебник / Р. Жмодик - Новосибирск: АНО Масс-Медиа-Центр, 2012. - 200с.

7. Карта добычи нефти [Электронный ресурс] // НОВОСИБИСКНЕФТЬГАЗ. - Режим доступа: https://www.novng.ru/ - Загл. с экрана.

8. Карта Новосибиской области [Электронный ресурс] // Яндекс.Карты. - Режим доступа: https://yandex.ru/maps/11316/novosibirsk-oblast/ - Загл. с экрана.

9. Крутеева, О.В. Цифровая экономика в Западной Сибири: перспективы и особенности регулирования [Текст]: статья в сборнике / О.В. Крутеева, А.О. Ткаченко - Новосибирск: Инновации и инвестиции, 2019. -115 с.

10. Панихидников, М.С. Речные ворота столицы Сибири [Текст]: интервью с генер. директором / М.С. Панихидников - Новосибирск: Веч. Новосибирск, 2001. - 7c. 
11. Поддержка инновации / Правительство Новосибирской области [Электронный ресурс] - Режим доступа: https://www.nso.ru/page/2534/_- Загл. с экрана.

12. Ростовцев, А.А. Рыбохозяйственная мелиорация поймы средней Оби: проблемы и перспективы [Текст]: статья в сборнике / А.А. Ростовцев - Новосибирск: Сибирский вестник сельскохозяйственной науки, 2015. - 74 с.

13. Русина А.Г. Вопросы повышения эффективности режимов работы Новосибирской ГЭС водохранилища [Текст]: статья в сборнике трудов конференции / А.Г. Русина, Г.Ж. Дургарян - Новосибирск: ФГБОУ ВПО НГТУ, 2017. - 27 с.

14. Стратегия социально-экономического развития Новосибирской области [Электронный ресурс] - Режим доступа: https://docviewer.yandex.ru/ - Загл. с экрана.

15. Толстых, Т.О. Трансформация промышленности в условиях цифровизации экономики [Текст]: статья в сборнике трудов конференции / Т.О. Толстых, Е.В. Шкарупета - Воронеж: ВГТУ, 2017. - 122 с.

16. Фадеенко, Н.В. Анализ состояния и перспектив развития земельных ресурсов прибрежной территории Новосибирского водохранилища [Текст]: статья в сборнике трудов конференции / Н.В. Фадеенко - Новосибирск: СГГА, 2011. - 115 с.

17. Щетинина, С.А. Инновационная активность Новосибирской области в условиях цифровой экономики [Текст]: статья в сборнике трудов конференции/ С.А. Щетинина, А.А. Попова - Новосибирск: НГУЭУ, 2019. - 226 с.

18. Digital economy \& society in the EU [Electronic Resource] // European Commission. URL: http://ec.europa.eu.

19. Nureev, R.M. Digital technologies: main directions of development [Text]: statistical compilation / R.M. Nureev, O.V. Karapaev - M.: Business and Management, 2018. - 533 p.

(C) А. Е. Донская, Е. В. Китаева, Л. К. Радченко, 2021 